\title{
Stabilization Missions - Lessons to Be Learned from Resilience-Based Peacebuilding
}

\section{Philipp H. Fluri}

\author{
WenZao University, Taiwan, https://english.wenzao.tw/
}

\begin{abstract}
International stabilization missions are often unsuccessful, as demonstrated by the fact that a large number of countries that have hosted such missions have also relapsed into conflict within 20 years. The author suggests looking to experiences of resilience-based peacebuilding for more successful examples. These remain largely unknown or ignored and still do not enjoy the attention they deserve, whether because the 'wrong' NGO crowd dominates peacebuilding programming, the 'wrong' departments and ministries are considered the main peacebuilding partners or the resilience-based projects simply are not costly enough to attract attention. A framework for resilience and examples from Guatemala, Liberia, Timor-Leste, and Afghanistan are discussed and lessons to be learned identified.
\end{abstract}

Keywords: liberal peacebuilding, stabilization, stabilization missions, SIGAR, Afghanistan, Guatemala, Liberia, Timor-Leste, resilience, resilience assessment, framework, resilience for peace.

\section{Introduction}

Liberal peacebuilding was the predominant concept for peace missions after the fall of the Soviet Union and the disappearance of the bipolar world system. Over time, the high costs associated with liberal peace missions and the rise of violent extremism and state sponsors of terrorism have led to rethinking the ends and means of intervention in fragile or conflict-affected states. Stabilization missions became the new paradigm for interventions, with a strong if not exclusive focus on security. The heavy focus on security is, however, not unproblematic. To illustrate, the Special Inspector General for Afghanistan Reconstruction (SIGAR) reports have analyzed and discussed in detail what exactly went wrong in the US-led stabilization effort in Afghanistan. In parallel to the emergence of stabili- 
zation missions, but rarely in close cooperation with them, the peacebuilding community developed a resilience-focused approach of identifying the local potential to develop and sustain positive peace. In this article, the author proposes to examine the role of resilience in peacebuilding, and how peacebuilding is a necessary complement to stabilization if viable self-sustained societies are to be the objective of international peace missions.

\section{How We Got Here - From Liberal Peacebuilding to Stabilization}

The end of the Cold War marked the beginning of an era of increasing intra-state conflict. "Liberal peace" was the guiding concept for international interventions under the auspices of regional organizations or the United Nations for almost two decades. ${ }^{1}$ Liberal peace's main assumptions entailed the rebuilding/building of state institutions on the basis of democracy, the rule of law, human rights, and promoting a market economy as the pathway to peace and prosperity.

This liberal peace concept has now mostly disappeared, both in practice and as a concept. Liberal peacekeeping turned out to be more complicated and costly than expected. It also turned out to be less unselfishly supported by local authorities than anticipated. Host governments tended to resist interventions and pressed for mandates that aligned with the self-interests of those in power. In the wake of these developments, the traumatic experience of the attacks on the US on September 11, 2001, and the global financial crisis of 2008-9, Western democracies shifted their focus from the promotion of liberal peace norms and principles to the mix of counterterrorism and stabilization efforts which has been characteristic of international deployments since the Afghanistan intervention.

Stabilization efforts, from the establishment of the UN Stabilization Mission in Haiti in 2004, included Western stakeholders' global partners and regional coalitions. This trend may have been welcomed as fair burden-sharing and a sign of properly empowered regional stakeholders taking on greater responsibility for regional security. The Mali deployment has, however, shown that UN stabilization missions can be challenged in their impartiality. They then risk being seen as not working in support of the totality of the affected population.

The agenda of counterterrorism and preventing and countering violent extremism (PVE/CVE) was promoted by the US and other western governments to become central issues on the agenda of organizations like the UN and the OECD. ${ }^{2}$ While US President George W. Bush launched the War on Terror agenda, this

1 For a map on ongoing (2020) Multilateral Peace Operations, see the SIPRI Website at https://www.sipri.org/sites/default/files/2020-06/mpo20_fill.pdf. By 'peace operation' we understand missions conducted by one or more of the different international organizations. As such peace missions are not clearly defined in international law. In a 'minimal' definition' suggested by ZIF, https://www.zif-berlin.org/en/what-peaceoperation, peace operations are: (1) deployed by an international organization; (2) with the consent of the respective host country; (3) in order to defuse crisis situations, end violent conflicts, and secure peace in the long term.

2 Ban Ki-moon's Plan of Action to Prevent Violent Extremism is to be seen in this light. 
continued under the Obama administration with a more sophisticated approach: the engagements in Iraq and Afghanistan were reduced, and a new, limited strategy endorsed with emphasis on special forces and drone strikes (targeted killings). Local troops were involved, trained, and equipped as part of the operational budget. The theater of engagement was thus enlarged by Mali, Niger, Somalia, and Yemen. Instead of addressing the root causes of conflicts, the approach sought to resolve such conflicts by use of force. Pressure was put on allies and partners to accept the new concept and take on part of the burden. The Trump presidency has hardly brought any conceptual change.

The inclusion of regional and ad hoc coalitions in UN peace operations also proved to be problematic. Local governments can be expected to have their own views of their neighbors and regional developments, including whom they see as a threat to regional stability. These views will necessarily have to be factored into mandates that seek to enlist regional cooperation.

With budgets shrinking and geopolitics returning, we are likely to see more emphasis on political stabilization through existing forms of government. Stabilization is portrayed as more effective and relevant to the current world situation and the needs of states experiencing conflict. However, given its heavy focus on security to the detriment of governance and development, it was only a question of time before its shortcomings would become apparent. This is already the case in Afghanistan and Mali.

Then, the enthusiasm over stabilization is likely to be limited in time, as it shifts the focus away from the root causes of conflict and development deficits, while enabling weak and corrupt governance, marginalization, exclusion, and lack of social cohesion. The reputation of the UN as the peacebuilding force has suffered accordingly. As John Karlsrud put it in his insightful article: "For the UN, the turn towards stabilization and counterterrorism is undermining the legitimacy of the organization and its work in mediation and humanitarian domains, and in particular UN peace operations, and the role of UN peace operations as a central tool in the international peace and security toolbox." ${ }^{3}$

\section{Lessons from the US Stabilization Experience in Afghanistan}

In a recent Lessons Learned report, the Special Inspector General for Afghanistan Reconstruction (SIGAR) examined the US stabilization effort in Afghanistan. ${ }^{4}$ The report details how the US Agency for International Development and the Departments of State and Defense tried to support and legitimize the Afghan government in contested districts from 2002 through 2017.

3 John Karlsrud, "From Liberal Peacebuilding to Stabilization and Counterterrorism," International Peacekeeping 26, no. 1 (2019), https://doi.org/10.1080/13533312.20 18.1502040.

4 Special Inspector General for Afghanistan Reconstruction, Stabilization: Lessons from the U.S. Experience in Afghanistan (SIGAR, 2018), https://www.sigar.mil/interactivereports/stabilization/index.html. 
Stabilization is not uniformly defined across relevant stakeholders and was consolidated as an explicit US strategy only in 2009. The SIGAR report surprises by its unusual candor and thoroughness. ${ }^{5}$ The forces in the NATO-led International Security Assistance Force saw themselves as under immense pressure and accountable for making fast progress. As a result, Afghan citizens were left with serious doubts as to the future of their personal safety and security and their government's staying power. Interestingly, once Afghan citizens actually were asked to join the discussion, ${ }^{6}$ a few of the coalition's assumptions were challenged: citizens found the behavior of Afghan government officials more threatening than the government's absence; they did not originally expect stabilization through extensive social services guaranteed and provided by the government (the Taliban had provided stability, "rule of law," and even a very limited social welfare system); they did not expect stabilization to succeed unless the contradictory interests of Afghanistan's leadership were overcome.

As a possible consequence of the limited results yielded by the stabilization process in Afghanistan, it could be argued to be better to forget about missions of that type. The SIGAR report does not stipulate such radical decisions. It rather alerts us to the fact that, even in the best conditions, stabilization takes time.

In light of frequent rotations, relaunches, and 'surges,' the stabilization effort in Afghanistan until 2018 appears not as one continuous effort and process over

5 According to the SIGAR report, the "U.S. government greatly overestimated its ability to build and reform government institutions in Afghanistan as part of its stabilization strategy" (note the wording: the US government's ability to build and reform government institutions - emphasis by the author). The stabilization strategy and the programs used to achieve it were thus "not properly tailored to the Afghan context." The large stabilization budget the United States devoted to Afghanistan in search of quick gains "often exacerbated conflicts, enabled corruption, and bolstered support for insurgents." Because the coalition "prioritized the most dangerous districts first, it continuously struggled to clear them of insurgents. As a result, the coalition couldn't make sufficient progress to convince Afghans in those or other districts that the government could protect them if they openly turned against the insurgents." In addition, "efforts to monitor and evaluate stabilization programs were generally poor," and successes "in stabilizing Afghan districts rarely lasted longer than the physical presence of coalition troops and civilians." The report concludes that "Stabilization was most successful in areas that were clearly under the physical control of government security forces, had a modicum of local governance in place prior to programming, were supported by coalition forces and civilians who recognized the value of close cooperation, and were continuously engaged by their government as programming ramped up."

6 The author recalls personal interviews with elected parliamentarians of all political parties in Kabul in 2010. The interviewees complained about having no say in the defense and security efforts and decision-making of the country which was said to have been entirely left to the president and his international advisors. They were equally left ignorant about the actual budget numbers, thus making a farce out of all capacitybuilding efforts for MPs and staffers on budget transparency and oversight. See DCAF Afghanistan Working Group, Afghanistan's Security Sector Reform Challenges (Geneva: DCAF, 2011), https://www.dcaf.ch/sites/default/files/publications/documents/ DCAF_RPS_Afghanistan.pdf. 
17 years, but rather as 17 one-year efforts, each with an inception and a phasingout period, with the cost of a 17-year process. Also, the type of 'stabilization' envisaged could only have been achieved with forces and approaches beyond the scope of the mission and the resources assigned to it. In other words: lasting stabilization paradoxically necessitates more than a stabilization mission and is not possible without a concomitant stabilization of government, civil society, and markets.

The SIGAR report concludes with recommendations on behalf of the US government. They can be considered a message to all governments interested in future stabilization missions:

- Even under the best circumstances, stabilization takes time. Without the patience and political will for a planned and prolonged effort, large-scale stabilization missions are likely to fail. The expected timeframe should be a minimum of 10 years.

- Most US government capabilities and institutions necessary in a largescale stabilization mission should be established and maintained between contingencies if they are to be effective when they matter most.

- Increased funding alone cannot compensate for stabilization's inherent challenges and believing that it can exacerbate those challenges.

- Physical security is the bedrock of stabilization.

- The presence of local governance is a precondition for effective stabilization programming.

- Stabilizing communities requires a tailored approach.

- Stabilization efforts must be rigorously monitored and evaluated.

- Successfully conceiving and implementing a stabilization strategy requires extensive local knowledge of the host-nation government and population.

The kinds of services the US government sought to help the Afghan government deliver were unnecessarily ambitious and not tailored to the environment. While improvements in healthcare, the formal rule of law, education, and agriculture services likely helped many Afghans, the coalition and the Afghan government aimed to provide Afghans in contested areas with an array of high-quality services that went well beyond what the Taliban had provided (and the population expected). They required a level of capacity and legitimacy far beyond what the government could offer, particularly in the time available. The coalition had sought to build peace for Afghans rather than with them.

\section{Peacebuilding}

Peacebuilding organizations may become increasingly involved in the prevention of violent extremism. Whereas the countering of violent extremism involves a strong security posture, the prevention of violent conflict and violent extremism 
does not. Moreover, as recognized by the UN General Assembly and the Security Council in 2016, the shift away from managing and responding to conflicts towards preventing them sustainably, inclusively, and collectively, can greatly reduce costs. $^{7}$

Peacebuilding has been defined in a variety of ways, depending on writers' and practitioners' priorities and experiences. The term 'peacebuilding' was coined by the Norwegian peace activist and scholar Johan Galtung in the 1970s, when he claimed that "peace has a structure different from peacekeeping and ad hoc peacemaking and that structures must be found that remove causes of wars and offer alternatives to war in situations where wars might occur." 8

Resilience-based peacebuilding, as practiced by the Geneva-based Interpeace International Organization for Peacebuilding seeks to identify context- and society-specific capacities existing at different levels of social organization. Capacities may consist of physical possessions, norms, and values, networks. They are sources of recourse to be accessed for survival and/or conflict transformation in case of threat or stress by natural or human causes. Rather than focusing on fragility and its removal, the resilience approach focusses on a society's endogenous resources and capacities and their strengthening.

If such resilience capacities exist, how can they be identified, nourished, and put to good use? The frameworks for assessing resilience seek to identify absorptive, adaptive, and transformative resilience capacity. The latter may have to be analyzed and, in fact, made conscious through a multi-stakeholder dialogue process. Such concrete work on common values, interests, and resources may well bring together actors who had previously been uncooperative against each other (the Guatemala experience). ${ }^{9}$ The resilience approach, rather than focusing solely on survival in a fragile environment, mobilizes "transformative instincts and capacities." 10

7 Pathways for Peace recommends a more concerted effort by policy makers, the integration of prevention agendas into development policies and efforts, inclusive and sustainable development as prevention and growth and poverty alleviation and departing from traditional economic and social policies. United Nations and World Bank, Pathways for Peace: Inclusive Approaches to Preventing Violent Conflict (Washington, DC: World Bank, 2018), p. iii, https://openknowledge.worldbank.org/ handle/10986/28337.

8 Johan Galtung "Three Approaches to Peace: Peacekeeping, Peacemaking, and Peacebuilding," in Peace, War and Defense: Essays in Peace Research, vol. 2 (Copenhagen: Ejlers, 1976), 282-304.

9 The author had the privilege of being invited to assess the process in Guatemala. For an academic version of the findings see Bernardo Arévalo de León, José Beltrán Dona, and Philipp H. Fluri, eds., Hacia una Política de Seguridad para la Democracia en Guatemala: Investigación y Reforma del Sector de Seguridad (Frankfurt: LIT Verlag, 2005).

10 In Timor-Leste, the National Working Group on Civic Education developed a Guide on Civic Education (based on resilience capacities previously identified). Additionally, the group suggested to put a National Coordination Council on Civic Education in place. The group had cooperatively concluded that lasting peace required the right conditions for good quality leadership at all levels. Such right conditions were understood 
Whereas natural disasters and humanitarian crises are situations that allow for a return to a status quo ante, conflicts are not. They are the product of dynamics within a society (or between societies) and the processes behind conflicts continue to evolve - resilience for peace must therefore be a capacity to understand and transform them.

Resilience does not automatically lead to peace. Resilience is a neutral concept and can bring about both positive and negative outcomes. Therefore, it is essential to carefully analyze which capacities have the potential to lead towards peace and which would need to be mitigated.

As mentioned above, local ownership-seen universally as essential to credible and sustainable peace processes - can be brought about by a resiliencebased approach. What is commonly seen as the starting point of peacebuilding interventions - the conflict assessment that identifies causes and drivers of conflict-may not be the ideal tool for bringing about such local ownership. A complementary resilience assessment focusing on a shared appreciation of existing capacities can provide a way forward for durable peace by engaging stakeholders in a dialogue on what brings and holds people together.

The experiences made with the Interpeace resilience approach led to a set of recommendations. A resilience-based approach can enrich peacebuilding strategies. It has also been shown to produce essential inputs for a national peacebuilding dialogue. Practitioners may, therefore choose to complement their conflict analyses with a resilience assessment in the very early stages of their work, designed to identify capacities existing at all levels of society. Not only should the resilience capacities potentially leading to positive outcomes be identified, but all resilience qualities, including potentially negative ones.

Resilience capacities may be expressed differently across different levels and sectors of society. In case of divergent perceptions of such capacities, peacebuilding actors should seek to address the differences in multi-stakeholder dialogues. A lack of systemic integration of such capacities may lead to a strengthening of "negative resilience."

Expressions of negative resilience need to be met with strategies that influence and incentivize using them for positive ends. They should not lead to the dismantling of the groups from which such negative resilience stems. Resilience assessment is - as the FAR program has shown-not only part of the pathway towards peacebuilding but in itself, an empowering peacebuilding exercise, mobilizing national stakeholders to take joint action.

Considering the enormous cost of a predominantly exogenous stabilization effort, the resilience approach is cost-effective and should thus be considered by all stakeholders.

to include mechanisms for leaders to be held accountable and an empowered population. 


\section{Assessing Resilience - Frameworks for Assessing Resilience (FAR)}

The results of the two-year program on defining and assessing resilience for peace launched in 2014 have been documented in a variety of publications, among them the Guidance Note for Assessing Resilience for Peace, and a series of publications on its pilot application in situ in Guatemala, Liberia, and TimorLeste. ${ }^{11}$ According to this view, successful conflict resolution presupposes not only analysis of the root causes, but also investigation and, ideally, strengthening of the endogenous capacities and resources to address and overcome such conflicts. The FAR approach thus goes beyond the traditional focus on fragility and finding solutions to it. Local stakeholders were invited to share views on how they understood resilience in dialogue with national practitioners, international scholars, expert-practitioners, and policy specialists. In the execution of the program, Interpeace partnered with the Harvard Humanitarian Initiative (HHI). The countries were selected on the basis of their post-conflict context and level of fragility, as well as their different geographical contexts. Liberia and Timor-Leste, at the time of the program implementation, were seeking to address state-building in the context of peacebuilding. Guatemala had one of the world's highest homicide rates.

Even in the most challenging situations, be they caused by conflict or natural disasters, individuals and communities can be found which seek to address and counter the situation. Peacebuilding interventions frequently overlook and neglect such efforts to the detriment of what could be a concerted peacebuilding effort rooted in local communities and their resources, which could be recruited for transformative processes transcending the mere response to fragility.

Conflicts often come with histories of social asymmetries and exclusion. The resilience approach leverages 'auto-immune' resources by which a society transforms circumstances and conditions which lead to the eruption of conflicts. Such resilience capacities can be found at different levels of society, and they may be interrelated or inter-relatable, both horizontally (with other communities and individuals) and vertically (with institutions of higher levels, including state institutions). This interrelatedness may seriously influence peacebuilding efforts, especially when not detected and mobilized. 'Resilience' is by itself value-neutral it concerns mainly the self-preservation instincts of a given entity within a larger context. It can manifest itself negatively if group solidarity comes at the expense of the success of peacebuilding for a society in its totality. It is therefore important that peacebuilding efforts comprehensively address such groups in their identities. This is especially relevant for (indigenous) ethnic groups with a high level of self-organization which provides not only a sense of identity but also "social capital," insofar as these groups therewith gain access to public goods which otherwise would be denied to them (such as education and healthcare).

11 All accessible via https://www.interpeace.org/programme/far-1/. For the above see "Using Resilience to Build Peace," Practice Brief: Resilience and Peacebuilding, Interpeace, 2016, p. $1 \mathrm{ff}$. 
In Guatemala these strong bonds clearly benefit the communities concerned but do not necessarily lead to greater cohesion of the society, nor trust in and willingness to cooperate with the institutions of the state:

As a result, indigenous groups become even more marginalised from the state. This is an example of how the inability to connect resilience capacities across levels-here between the community level and state level-can feed into conflict dynamics. There is thus a powerful case to be made for identifying informal leaders or intermediary institutions that can bridge the divide between the indigenous community and the state, so that the strong social cohesion within indigenous communities can be harnessed for greater peace at the society level. ${ }^{12}$

The question that needs to be asked in such a case is then: how can the cooperation between groups be improved? And what policies would need to be put in place to enhance the mechanisms for cooperation typical for a given society? Resilience does not necessarily and automatically lead to peace.

Similarly, stakeholders in Timor-Leste identified culture, religion, leadership, law, and security as ambivalent and at times used for exclusionary purposes. Therefore, a resilience analysis should lead to a careful distinction of factors potentially enabling peace from others that need to be mitigated. The essential difference of a resilience-based approach from a fragility-focused one becomes evident in this context: whereas the fragility-focused approach would rather stop and eliminate negative factors, the resilience-based approach would seek to build on existing capacities while mitigating negative factors.

Whereas traditional peacebuilding would start with an analysis of conflict causes and drivers, the resilience-based approach complements such analysis with one of the resilience resources-and in doing so by enlisting local stakeholders-situates the discourse in the midst of local ownership while being solution-oriented from the beginning. Therefore, it is recommended to complement the conflict analysis at the beginning of a program cycle with a mapping of resilience capacities at all levels of society, including those of an ambivalent or negative connotation. Negative resilience can be avoided by paying attention to how resilience capacities are expressed and put to use at different levels of society. Programs then need to be designed in a way that allows for the mitigation and positive use of such capacities.

The FAR program would seem to have demonstrated that resilience is indeed a useful addition to the peacebuilding approach with the potential to inform peacebuilding practice in ways that help prevent the onset and re-emergence of conflict and foster sustainable peace. Resilience strongly enhances the conflict prevention agenda and presents an added value to the international community. While an assessment of resilience aims at influencing action and policy towards sustainable peace at all levels in the long term, the FAR program has demonstrated that assessing resilience is also an empowering peacebuilding exercise in

12 "Using Resilience to Build Peace." 
and of itself as it mobilizes in-country stakeholders to take collective action towards peace. This holds great potential both in terms of prevention and costeffectiveness and should therefore be considered by donors in all initiatives for peacebuilding, state-building, humanitarian aid, and development. Apart from its inherent peacebuilding potential, the resilience approach presents the opportunity for greater collaboration among practitioners, donors, and policymakers working in various fields of international development.

\section{Conclusions}

Peacebuilding programs and international peace missions traditionally take place in relative isolation from each other. The way peace missions are set up leaves little flexibility for mandate adjustments once a mandate has been negotiated and budgeted. Against a 'mechanistic' stabilization mandate implementation that rests on a strong security posture to which all other activities are subordinated if noticed at all, the author argues in favor of peace missions informed by resilience-based peacebuilding. Societies could likely be consolidated and made viable again in a locally owned cooperative process based on resilience capacities already existent within (parts of) the society in question. Organizations and nations participating in peace missions would thus be spared the embarrassment of having to leave countries with mission objectives still unaccomplished.

It is the peacebuilding community that supposedly has the linguistic competence and leadership qualities to find common language and discuss and define common values, norms, and procedures in difficult situations. For this to happen, the peacebuilding community and the ministries and organizations supporting them should envisage stepping out of the cocoon of isolation they have been working in by proactively starting to practice in regard to the security community what they themselves do best on the ground: reach out, find that common language, and define policy frameworks for enduring cooperation.

\section{Disclaimer}

The views expressed are solely those of the author and do not represent official views of the PfP Consortium of Defense Academies and Security Studies Institutes, participating organizations, or the Consortium's editors.

\section{Acknowledgment}

Connections: The Quarterly Journal, Vol. 19, 2020 is supported by the United States government.

\section{About the Author}

Philipp H. Fluri, DDr., is a co-founder and former deputy director of the Geneva Centre for the Democratic Control of Armed Forces (DCAF) and executive-in-residence of the Geneva Centre for Security Policy. After many years of working as a political advisor and educator on all continents, he is currently a visiting professor at WZU Taiwan. E-mail: drphilippfluri@gmail.com. 